\title{
Chemoradiation Including Paclitaxel for Locally Recurrent Muscle-invasive Bladder Cancer in Elderly Patients
}

\author{
LUKAS KÄSMANN, LISA MANIG, STEFAN JANSSEN and DIRK RADES \\ Department of Radiation Oncology, University of Lübeck, Lübeck, Germany
}

\begin{abstract}
Background/Aim: To evaluate outcomes and toxicities of chemoradiation with a less intensive paclitaxel regimen for locally recurrent bladder cancer. Patients and Methods: Three elderly patients received simultaneous chemoradiation for recurrent muscle-invasive bladder cancer. Chemotherapy included two courses (three times $25 \mathrm{mg} / \mathrm{m}^{2}$ over 1.5 weeks) of paclitaxel. Radiotherapy doses were 59.4 Gy to the bladder and 50.4 Gy to regional lymph nodes. Survival, local control and toxicities were retrospectively evaluated. Results: One patient died after 71 months, two were alive after 69 and 98 months, respectively. No local recurrence was not observed. Five-year survival and local control rates were $100 \%$. Two patients experienced grade 1 acute dysuria, one patient grade 1 diarrhea. Late toxicities were also mild; two patients had grade 1 dysuria. Conclusion: Chemoradiation with a less intensive paclitaxel regimen resulted in excellent 5-year results and was very well tolerated. It may be a reasonable option for elderly patients who cannot tolerate more intensive approaches.
\end{abstract}

Muscle-invasive carcinoma of the urinary bladder is a relatively uncommon type of cancer (1). Following treatment of the primary tumor such as surgery or organ-sparing chemoradiation, up to $60 \%$ of patients develop a local recurrence $(2,3)$. Some of these recurrences may be treated with transurethral resection of the bladder tumor (TURBT). However, this type of surgical intervention is reasonably possible only very few times. In the vast majority of patients with recurrent muscle-invasive bladder cancer, a TURBT is not sufficient (2). In these situations, one possible treatment

This article is freely accessible online.

Correspondence to: Professor Dirk Rades, M.D., Department of Radiation Oncology, University of Lübeck, Ratzeburger Allee 160, 23538 Lübeck, Germany. Tel: +49 45150045401, Fax: +49 45150045404, e-mail: rades.dirk@gmx.net

Key Words: Muscle-invasive bladder cancer, local recurrence, chemoradiation, paclitaxel, outcomes, toxicities. option would be radical cystectomy, which can be associated with high rates of serious complications and even surgeryor anesthesia-related deaths $(2,4,5)$. Therefore, many patients, particularly elderly patients and those with a poor general condition or serious co-morbidity are not suitable for radical surgery and considered candidates for bladderpreserving simultaneous chemoradiation. Cisplatin is considered the standard agent for chemoradiation of bladder cancer (3). However, a considerable number of patients, particularly those with impaired renal function or hearing problems, cannot receive cisplatin. A previous study investigated the role of monotherapy with paclitaxel as a radiosensitizer for patients with bladder cancer assigned to radiotherapy (6). In that study paclitaxel was given twice per week during the whole course of radiotherapy (6 to 6.5 weeks) with doses of $25-35 \mathrm{mg} / \mathrm{m}^{2}$ per administration. Although also younger patients were included in that study, $24 \%$ of the patients could not receive their chemoradiation as planned due to treatment-related toxicity. Since the general condition of patients presenting with a recurrent malignancy is often worse than at the time of the first diagnosis and treatment, many patients with recurrent bladder cancer may not be able to withstand the more intensive paclitaxel regimen when given simultaneously with radiotherapy. This likely would apply particularly to elderly patients. Therefore, we treated three elderly patients, who could not receive cisplatin and would likely not be able to tolerate a more intensive chemoradiation approach, with a less intensive paclitaxel regimen. The treatment outcomes and treatment-related toxicities are reported.

\section{Patients and Methods}

Three elderly male patients with a histologically confirmed local recurrence of muscle-invasive bladder cancer were referred for chemoradiation. Their characteristics are given in Table I. Due to older age and comorbidity, standard chemotherapy with cisplatin was not possible and patients were assigned to simultaneous chemoradiation with paclitaxel. It was questionable whether these patients were able to tolerate a more intensive paclitaxel regimen as used in a previous study. Therefore, patients in the present study received a less intensive paclitaxel regimen with two courses, each 
in vivo $31: 239-242(2017)$

Table I. Patient characteristics.

\begin{tabular}{lccccc}
\hline & $\begin{array}{c}\text { Age at } \\
\text { chemoradiation }\end{array}$ & $\begin{array}{c}\text { Karnofsky } \\
\text { score }\end{array}$ & $\begin{array}{c}\text { Initial tumor } \\
\text { stage }\end{array}$ & $\begin{array}{c}\text { Histologic } \\
\text { grade }\end{array}$ & $\begin{array}{c}\text { Time from first diagnosis of bladder cancer to } \\
\text { chemo-radiation of the recurrence }\end{array}$ \\
\hline Patient 1 & 79 years & $80 \%$ & T2 N0 M0 & 3 & 15 months \\
Patient 2 & 69 years & $60 \%$ & T3 N1 M0 & 3 & 12 months \\
Patient 3 & 75 years & $90 \%$ & T4 N1 M0 & 3 & 7 months \\
\hline
\end{tabular}

consisting of three administrations of $25 \mathrm{mg} / \mathrm{m}^{2}$ over 1.5 weeks, on an individual decision. Paclitaxel was given intravenously as an infusion over 1 hour. Premedication included $2 \mathrm{mg}$ of clemastine, $1 \mathrm{mg}$ of granisetron and $8 \mathrm{mg}$ of dexamethasone also given intravenously.

Radiotherapy was performed with a high energy photon beams from a linear accelerator. Initially, the bladder including the local recurrence and the regional lymph nodes received a total dose of $50.4 \mathrm{~Gy}$ with doses per fraction of $1.8 \mathrm{~Gy}$ given on five consecutive days each week. Subsequently, a radiation boost of $9 \mathrm{~Gy}(5 \times 1.8 \mathrm{~Gy})$ was administered to the bladder.

Patient outcomes in terms of survival, local control, acute toxicity and late toxicity were retrospectively evaluated. The patients' survival time and freedom from another local recurrence were calculated from the last day of chemoradiation given for local recurrence (Kaplan-Meier-method). Toxicities were evaluated with the Common Terminology Criteria of Adverse Events (CTCAE) classification, version 4.3.

\section{Results}

Out of the three patients, one patient died after 71 months. The other two patients were still alive after 69 and 98 months, respectively. Thus, the 5-year survival rate was $100 \%$. Another locoregional following chemoradiation was not observed. Thus, the 5-year local control rate also was $100 \%$. In all three patients, the bladder was still preserved at their last follow-up. Outcomes following chemoradiation are summarized in Table II.

Acute toxicities were very mild; two patients experienced grade 1 dysuria and one patient grade 1 diarrhea. Late toxicities were also very mild; two patients had a grade 1 dysuria and one patient no late toxicity at all. Maximum acute and late toxicities are summarized in Table III.

\section{Discussion}

Although carcinomas of the urinary bladder belong to the less common types of solid cancer, many studies have been performed to improve the prognosis of this group of patients (7-10). This applies to all situations including treatment at the time of first diagnosis of the disease as well as treatment of recurrent or metastatic disease. For a local recurrence of muscle-invasive bladder cancer, a TURBT alone is largely not sufficient $(2,3)$. Patients can be treated with either
Table II. Outcomes after chemoradiation.

\begin{tabular}{lcccc}
\hline & $\begin{array}{c}\text { Another local } \\
\text { recurrence }\end{array}$ & $\begin{array}{c}\text { Bladder } \\
\text { preserved }\end{array}$ & Death & $\begin{array}{c}\text { Maximum follow-up } \\
\text { (months) }\end{array}$ \\
\hline Patient 1 & No & Yes & Yes & 71 \\
Patient 2 & No & Yes & No & 98 \\
Patient 3 & No & Yes & No & 69 \\
\hline
\end{tabular}

radical cystectomy or organ-preserving chemoradiation, generally preceded by a TURBT. For organ-preserving treatment of the primary tumor, chemoradiation was shown to result in more favorable outcomes than radiotherapy alone $(2,3)$. This would likely also apply to a locally recurrent tumor if the treatment is given with curative intention. Cisplatin is the standard chemotherapeutic agent used for simultaneous chemoradiation of bladder cancer. Many patients cannot receive cisplatin due to advanced age and concomitant diseases. For these patients, paclitaxel has been reported as a reasonable alternative. However, in a previous report using doses of $25-35 \mathrm{mg} / \mathrm{m}^{2}$ of paclitaxel administered twice per week during the whole course of 6 to 6.5 weeks of radiotherapy, every fourth patient did not complete his planned treatment mostly due to treatment-related diarrhea (6). Since that study included patients younger than in the present series and was performed mainly in patients receiving primary treatment for bladder cancer, the proportion of patients not sufficiently tolerating this more intensive regimen would likely be higher in elderly patients receiving chemoradiation for recurrent bladder cancer. Therefore, we used a less intensive paclitaxel regimen in very few patients who could not receive cisplatin and would likely not be able to withstand an intensive chemoradiation regimen. In the present study, the less intensive approach was extraordinarily well tolerated with maximum acute and late toxicities being only grade 1 . In the previous study, 13 of 42 patients $(31 \%)$ died, 7 patients $(17 \%)$ due to bladder cancer (6) and 3 patients $(7 \%)$ due to development of local recurrence. In another study of 68 patients receiving organpreserving treatment for primary muscle-invasive bladder cancer, 34 patients $(50 \%)$ were treated with chemoradiation 
Table III. Acute and late toxicities.

\begin{tabular}{lcccc}
\hline & $\begin{array}{c}\text { Maximum } \\
\text { acute dysuria }\end{array}$ & $\begin{array}{c}\text { Maximum acute } \\
\text { gastrointestinal toxicity }\end{array}$ & $\begin{array}{c}\text { Maximum } \\
\text { late dysuria }\end{array}$ & $\begin{array}{c}\text { Maximum late } \\
\text { gastrointestinal toxicity }\end{array}$ \\
\hline Patient 1 & Grade 1 & Grade 0 & Grade 1 & Grade 0 \\
Patient 2 & Grade 0 & Grade 1 & Grade 1 & Grade 0 \\
Patient 3 & Grade 1 & Grade 0 & Grade 0 & Grade 0 \\
\hline
\end{tabular}

including cisplatin ( $25 \mathrm{mg} / \mathrm{m}^{2}$ on days 1-5 and 29-33), 27 patients $(40 \%)$ with chemoradiation including paclitaxel (25$35 \mathrm{mg} / \mathrm{m}^{2}$ twice weekly during the whole course of radiotherapy) and 7 patients $(10 \%)$ with radiotherapy alone (11). The 5-year survival rate in that study was $45 \%$. When comparing the results of these previous studies including more intensive chemoradiation programs mainly for the primary treatment of muscle-invasive bladder cancer to the results of our present series, the results of the present study with a 5-year survival rate of $100 \%$ can be considered quite promising $(6,11)$. Since the current study included only a very small number of patients, its findings need to be confirmed in a larger prospective trial. However, until such a trial is available, the promising results of the present study may offer a reasonable option of chemoradiation for recurrent bladder cancer in elderly patients or patients with a poor performance status and a high comorbidity index (12).

In conclusion, chemoradiation with a less intensive paclitaxel regimen resulted in excellent outcomes at 5 years and was very well tolerated. This new regimen may be a reasonable option for elderly patients who cannot tolerate a more intensive chemoradiation approach.

\section{Conflicts of Interest}

On behalf of all Authors, the corresponding Author states that there is no conflict of interest related to this study.

\section{References}

1 Siegel RL, Miller KD and Jemal A: Cancer statistics, 2016. CA Cancer J Clin 66: 7-30, 2016.

2 Koga F and Kihara K: Selective bladder preservation with curative intent for muscle-invasive bladder cancer: a contemporary review. Int J Urol 19: 388-401, 2012.

3 Rödel C, Grabenbauer GG, Kühn R, Papadopoulos T, Dunst J, Meyer M, Schrott KM and Sauer R: Combined-modality treatment and selective organ preservation in invasive bladder cancer: long-term results. J Clin Oncol 20: 3061-3071, 2002.
4 Konety BR, Allareddy V and Herr H: Complications after radical cystectomy: analysis of population-based data. Urology 68: 5864, 2006.

5 Manoharan M, Ayyathurai R and Soloway MS: Radical cystectomy for urothelial carcinoma of the bladder: an analysis of perioperative and survival outcome. BJU Int 104: 1227-1232, 2009.

6 Müller AC, Diestelhorst A, Kuhnt T, Kühn R, Fornara P, Scholz HJ, Dunst $J$ and Zietman AL: Organ-sparing treatment of advanced bladder cancer: paclitaxel as a radiosensitizer. Strahlenther Onkol 183: 177-183, 2007.

7 Ecke TH, Arndt C, Stephan C, Hallmann S, Lux O, Otto T, Ruttloff $\mathrm{J}$ and Gerullis $\mathrm{H}$ : Preliminary results of a multicentre study of the UBC rapid test for detection of urinary bladder cancer. Anticancer Res 35: 2651-2655, 2015.

8 Noel N, Couteau J, Maillet G, Gobet F, D'Aloisio F, Minier C and Pfister C: TP53 and FGFR3 Gene Mutation Assessment in urine: Pilot study for bladder cancer diagnosis. Anticancer Res 35: 4915-4921, 2015.

9 Jana BR and Zhou Y: Novel molecular targets for the therapy of urothelial cancer. Anticancer Res 35: 4557-4567, 2015.

10 Kuo JH, Shih TY, Lin JP, Lai KC, Lin ML, Yang MD and Chung JG: Cantharidin induces DNA damage and inhibits DNA repairassociated protein expressions in TSGH8301 human bladder cancer cell. Anticancer Res 35: 795-804, 2015.

11 Dunst J, Diestelhorst A, Kühn R, Müller AC, Scholz HJ and Fornara P: Organ-sparing treatment in muscle-invasive bladder cancer. Strahlenther Onkol 181: 632-637, 2005.

12 Guancial EA, Roussel B, Bergsma DP, Bylund KC, Sahasrabudhe D, Messing E, Mohile SG and Fung C: Bladder cancer in the elderly patient: challenges and solutions. Clin Interv Aging 10: 939-949, 2015.
Received January 10, 2017

Revised February 10, 2017

Accepted February 13, 2017 